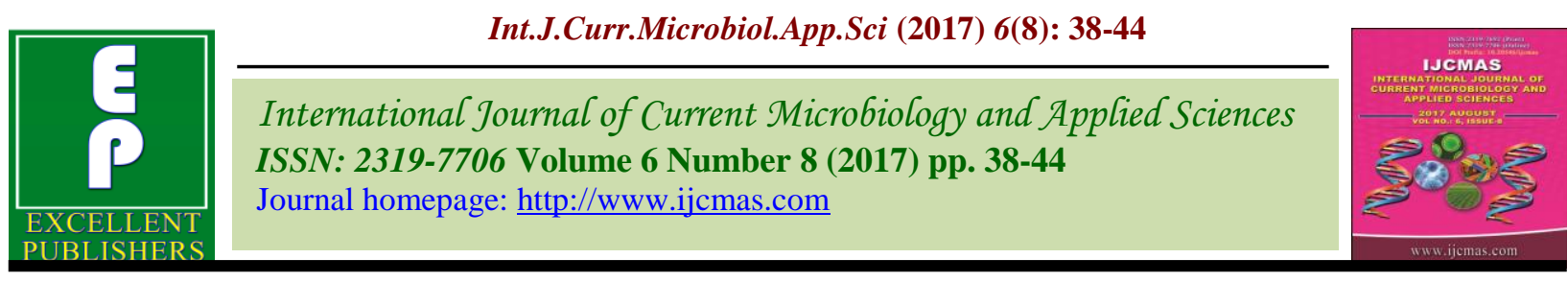

Review Article

https://doi.org/10.20546/ijcmas.2017.608.006

\title{
Longan (Dimocarpus longan Lour) Processing: A Review
}

\author{
K. Prasad ${ }^{1 *}$, Pallavi Neha ${ }^{4}$, Milan Kumar Lal ${ }^{2}$ and Abhay Kumar Gaurav ${ }^{3}$ \\ ${ }^{1}$ Division of Postharvest Technology, ${ }^{2}$ Division of Plant Physiology, ${ }^{3}$ Division of Floriculture \\ and Landscaping, Indian Agricultural Research Institute, \\ New Delhi-110012, India \\ ${ }^{4}$ Division of Postharvest Technology, Indian Institute of Horticultural Research, \\ Bengaluru, Karnataka-560089, India \\ *Corresponding author
}

\section{A B S T R A C T}

Longan (Dimocarpus longan Lour) is the delicate fruit of immense value. Its production in Keywords

Longan,

Post-harvest

management,

Processing.

Article Info

Accepted:

04 June 2017

Available Online:

10 August 2017

Asia pacific regions countries including China, Thailand, Vietnam, Laos and India has shown a rise in last few years. Longan has a widespread postharvest use but, the major hindrance in its PHM (Postharvest management) is its poor shelf life. Its proper postharvest management starts from judging horticultural maturity and retaining all its sensory characteristics which are important for its consumer appeal. There are several problems which need to be taken care during its PHM. Flavour loss, fruit breakdown during rains and rind ageing are few of such its quality deteriorating factors. Knowledge of information regarding PHM techniques determines the shelf life of fruits. The important PHM techniques include a selection of cultivars with respect to consumer preference, maturity indices, postharvest treatment of forced air or hydro-cooling, fumigation with sulphur dioxide and lastly storage of fruits at low temperature. longan fruit can also be dried, canned or frozen and can be made available throughout the year. The knowledge of postharvest processing techniques along with varietal selection will help growers to enhance its processing level in a holistic approach.

\section{Introduction}

Longan (Dimocarpus longan; Family: Sapindaceae) is subtropical fruit crop of china and few other countries of Asia pacific regions (Huang, 1995). Because of its delicate flavour and sweet taste longan has is becoming trending in recent decade in the South-East Asian region and all over the world. It is consumed as fresh or in the processed forms such as dried flesh and the canned product. This fruit is similar to lychee and is being referred as 'little brother of lychee' and also known as 'Dragon's eye' fruit by its regional title 'pinyin', which suggests 'dragon eye' (Jiang et al., 2002). It has a very poor shelf life which challenging postharvest technologist. It is mainly grown in the region like China, Thailand, Vietnam, and Laos, also in the recent year, its demand has been increasing exponentially (Qiu, 2013). Growers can get higher income from this crop by following proper harvesting methods and postharvest management which are a limiting factor in these regions (Chen et al., 2011). Longan can be preserved by various forms like frozen, canned, dried etc and longer availability can be achieved (Xu, 2004). It has 
a large range of uses (Menzel and Waite, 2005). High returns are possible, only when the crop is managed properly keeping account of postharvest processing aspects rather than relying only on preharvest management.

\section{Pre-harvest factors deciding postharvest quality of longan fruits}

\section{Economically important species having postharvest importance}

Subhadrabandhu and Huang reported that under the family Sapindaceae, the genus Dimocarpus is reported to have six different trees and shrubs (Subhadrabandhu, 1990; Huang et al., 1999). Five species (Dimocarpus longan, Dimocarpus dentatus, Dimocarpus gardneri, Dimocarpus foveolatus, and Dimocarpus fumatus) are found in Asia, Sri Lanka and India and also some parts in the Malaysia. The commonly grown species is Dimocarpus longan while the commercially grown taxon is Dimocarpus longan spp. longan var. longan.

Generally, in fruit crops, postharvest life and fruit quality affected largely by pre-harvest factors mainly the selection of cultivars (Prasad and Sharma, 2016). Varietal recommendations of the horticultural crop are of utmost importance and it should be done according to the climatic condition of the growing region. The work of identification and evolving of varieties in Asia pacific region is chiefly contributed by China, Taiwan, Florida, and Vietnam (Pham et al., 2013; Qiu, 2014). Thus, varieties having better postharvest attributes play an important role in the processing industry. Varieties like 'Wu Yuan' (canning) 'She p' i' (largest fruit) 'Kohala' (large fruit, small seed, aromatic flesh), 'Chuliang' (drying purpose) 'Shixia'(crisp flesh, high TSS) 'Wuyuan' (fresh and drying) 'Fuyan '(canning) 'Daw' (earlymaturing cultivar) 'Chompoo' (pink colored, sweetish, aromatic) 'Biew Khiew' (thick skinned longer shelf life) 'Fengko' (yellow fleshed), 'Tieuhue', 'Longnhan' (high bearing capacity), and 'Kohala' (high aril recovery) are found to be choicest varieties for postharvest processing in Asia- pacific region.

\section{Composition of fruit}

The export quality of fruit ranges from 67 to 78 percent of the total edible fruit. The calorific value of longan fruit is $458 \mathrm{~kJ} / 100 \mathrm{~g}$, while vitamin $\mathrm{C}$ content is $60.1 \mathrm{mg} / 100 \mathrm{~g}$ fresh weight. The high sugar content and the high shelf-life of the fruit make it promising for cultivation (Cheng et al., 2014). In the Asian cultivars, the sugar quantity is higher as compared to the other cultivar that is grown all over the world. The shelf life of the fruit can be extended by processing the fruit by freezing, canning and drying (Han et al., 2010).

\section{Fruit setting and morphology}

Longan flower has a panicle and is composed of staminate, pistillate and hermaphrodite flowers. It is a cross-pollinated species and in order to achieve the cross pollination it undergoes duo dichogamy. Flowering for fruit formation occurs during mid-summer or autumn and sometimes also born on the shoots produced in the spring on the terminals which have not set panicles. It takes 5-7 months from the day of flowering to the day of harvest depending upon the cultivars and climate. The fruit weighs around 5 to $20 \mathrm{~g}$ and high-quality fruit may range from 14 to $18 \mathrm{~g}$ per fruit. The rind of the fruit is tough and leathery and it changes colour from greenish yellow to yellowish brown with the advancement of the maturity and a similar pattern is also observed in pericarp (Shi et al., 2015). The tubercles are typically flattened or indistinct and related species the rind tubercles are very distinct. Aril part of fruit constitutes 60 to 70 percent of the total fruit weight. The taste of fruit is sweet and sour 
which indicate it contains lots of organic acids which makes it juicy and have lots of flavour in it. (Cheng et al., 2014)

Various reports suggest that fruit morphology is very important for deciding the storage and shelf life. The fruits, in drooping clusters, are globose, $1.25-2.5 \mathrm{~cm}$ in diameter, with thin, brittle, yellow-brown to light reddish-brown rind, more or less rough (pebbled), the protuberances much less prominent than those of the lychee (Guo et al., 2012). The flesh of the fruit is known as aril and it is white in colour with musky, sweet in taste and is translucent in nature. The seed is round, black, shining with a circular spot at the base and giving it the shape of an eye. It is delicate and may get damaged during the process of transport (Shi et al., 2015).

\section{Management of fruit growth for proper harvest}

The high night temperature beyond $25^{\circ} \mathrm{C}$ is detrimental to fruit development while, above $40^{\circ} \mathrm{C}$ cause damage with a drop which is accelerated by high wind speed. The best temperature in the Asian region is $20-25^{\circ} \mathrm{C}$ for flower and fruit development. Fruit thinning is practised to increase the fruit size as only large fruits $(2.5 \mathrm{~cm}$ in diameter or 18 $\mathrm{g}$ in weight) attract a premium price and to reduce biennial bearing. It is done four to six weeks after fruit set when they are of pea size. The rainfall required for this fruit crop ranges from 1,200 - 1,400 $\mathrm{mm}$ and critical period of irrigation are; panicle emergence, fruit set until the maturation of the post-harvest growth flush. Irrigation is withdrawn before the next flowering which allows flower initiation for the next season's crop (Cheng et al., 2014; Shi et al., 2015).

\section{Maturity, harvesting and packaging}

The marcotted longan tree starts bearing the fruit after four years of plantation and generally yields $2-3 \mathrm{~kg}$ per tree. After the age of fifteen years, it yields around $150-100 \mathrm{~kg}$ per tree and declines after thirty-five year (Pei et al., 1997). But, the variation in the yield has been observed from year to year and also in the biennial bearing in most of the cultivar. Fruits should be picked twice at an interval of 7 - 10 days. Most cultivars lose flavour if harvesting is delayed and when fruits are mature (Han et al., 2011). The fruit panicles bearing one or two leaves are harvested. Removal of too many leaves may lead to a decrease in the bearing of the flowering and fruit and also panicles (Chen et al., 2011).

Longan fruits with stalk intact (about 21-22 $\mathrm{kg}$ ) are packed in $35 \mathrm{~cm} \times 50 \mathrm{~cm}$ round woven bamboo baskets lined with longan leaves (Han et al., 2010). The export quality fruits are detached from the panicles and are packed in the corrugated boxes or may be in the plastic boxes. Harvesting should be avoided during rainy season due to the risk of breakdown after harvest (Han et al., 2010; Shi et al., 2015; Pham et al., 2016). Although there is a lot of challenges to the researchers to recommend species specific grading techniques (but on the same time regular attempts are performed to fill up the gaps with respect to grading in many countries (Pham et al., 2016).

\section{Management of fruit deformities}

The major pest of longan is stink bug (Tessaratoma javanica) which can destroy and ruin the bloom in the year of low flowering. The adult bug feed in the panicles and young fruits and newly developed shoots of longan, causing the desiccation of the infested part of the tree. The natural predator of stink bug is Anastatussp, Micropanurus sp. and Eupelmid sp. Bat and flying fox is a major problem in Australia and Thailand, with only measure to protect the tree is either to give the protective net around the perimeter of the orchard and over the trees or 
electroulation. Witches broom under biotic and irregular flowering and biennial bearing under the abiotic condition is a problem faced by commercial orchards. Options like fruit bagging are also being explored depending on the reason for reducing fruit deformities in pre-harvest stage (Zheng et al., 2009; Mo, 2011).

\section{Postharvest factors for processing of longan}

\section{Storage condition and Post-harvest treatments}

In general, postharvest treatment for fruits improves the postharvest quality to a significant level (Prasad et al., 2016a). The longan in this respect has high sugar content and has a short shelf life of fruit. The ambient condition for harvesting longan is $\left(25^{\circ}-31^{\circ} \mathrm{C}\right)$ and delay it from harvesting may lead to ring ageing and it start turning brown within 3-4 days. This problem can be resolved by using proper method of harvesting and immediate precooling (Shi et al., 2015).Proper storage is very important for this crop to extend shelf life for few days. Longan is subjected to hydro cooling or forced air cooling which leads to longer storage period when coupled with low temperature during storage. It is susceptible to chilling injury when stored at the temperature below $7^{0} \mathrm{C}$; the symptoms include the water soaking areas and browning of the pericarp. The fruit is prevented from fungal growth by fumigation with sulphur dioxide and this is the ideal method to increase shelf life (Li et al., 2009). Fumigation of sulphur dioxide for 20 minutes and storing the 'Shixia' longan fruits at $4{ }^{\circ} \mathrm{C}$ produced 100 percent of good fruits after 28 days of storage without chilling injury (Han et al., 2000; Holcroft et al., 2005). Sulphur fumigation reduces the ageing in longan by reducing the activity of polyphenol oxidase (PPO) (Wu et al., 1999). But demerit of using sulphur dioxide is toxicity to a human being (Tongdee, 1994). The other alternative reported is the dipping of fruits in the organic acids like malic acid, oxalic acid, formic acid and citric acid + ascorbic acid for 5-10 minutes (Whangchai et al., 2006) or acid coating (Apai et al., 2009a).

\section{Processing of fruits into value added products}

Longan fruit mature under high temperature and humidity therefore harvested fruit deteriorate rapidly and result in having a very short shelf life. To overcome this problem of longan fruits, they are processed into a number of value-added products through drying, canning, and freezing. Drying the fruit, either intact or after removal of the pericarp is a practical way of preserving the longan fruit. Subhadrabandhu, (1990) has described in detail the processing of longan into dried fruits where fruit is dried either intact or with pericarp removed. The process of drying of longan fruits starts by boiling it for five minutes, followed by sun or oven drying at $55^{\circ} \mathrm{C}$. When the fruits start to dry the temperature is raised to $70^{\circ} \mathrm{C}$ for approximately 19-20 hours until they are completely dried. The dried longan fruits contain moisture of about 18-19 percent and have a high sugar content of $60-65^{\circ}$ Brix.

Under freeze processing the fruit can be frozen with its skin in an airtight container, after thawing it, same quality can be retained without any loss in the appearance. Canning can be done by adding little or no sugar and using its own sweet juice for preservation for the long time (Cheng et al., 2014; Pham et al., 2016). For canning, the cultivars having large and small size fruits are preferred.

Apart from the commercial postharvest use, there are several household uses of this fruit. An alcohol is made from longan by 
macerating it and is known as Liqueur (Koslanund et al., 2008). The flesh of it is used as herbal medicine for insomnia, stomach ache and antidote for poison. The seed of longan is also used as shampoo due to the high content of saponin which serves as a styptic. The dried leaves and flower of longan contain quercetin which is anti-cancerous in nature. A decoction of the dried flesh is taken as a tonic and for the treatment for insomnia and neurasthenic neurosis. Flowers and fruits reported having anti-cancerous properties (Lin et al., 2001a, Marisa, 2006). Household use of canned longan, dried 'longan nuts', longan nectar and frozen longan are also taken up. Thus longan can be used in various forms through a wide range of postharvest products if processed successfully (Che et al., 2011; Cheng et al., 2014; Shi et al., 2015).

\section{Future thrust}

There are substantial canning factories for longan in Asia Pacific region and with proper pre-harvest and postharvest management the quality of this fruit can be maintained and exported in other countries (Che et al., 2011; Qiu, 2014). Selection of recommended cultivars and proper postharvest management is must for high returns from this crop (Lin et al., 2011; Qiu, 2014; Shi et al., 2015) and for the survival of the longan industry. The intercultural operations, the maturity of fruits, nutrition to the plant cannot be ignored for the postharvest fruit quality. Postharvest management of this crop not only enhances its production and export in the Asia pacific region but it will also ensure good returns to the growers (Lin, et al., 2001a, 2002; Holcroft, et al., 2005; Qiu, 2014; Cheng et al., 2014).

\section{References}

Apai, W., Sardsud, V., Boonprasom, P., Sardsud, U., 2009. Effects of chitosan coating with citric acid and potassium sorbate on postharvest decay and browning of longan fruit during cold storage. Acta. Hortic. 837, 181-188.

Chen YH, Lin HT, Lin YF, Zhao Y.F., Zhang J.N., 2011. Effects of phomopsis longanae infection on lipoxygenase activity and fatty acid constituents of membrane lipids in the pericarp of harvested longan fruits. J Trop Subtrop Bot 19: 260-266.

Chen, M.N. 2011. Comparative study on photosynthetic characteristics of different longan varieties. Fujian Fruits 3:9-12.

Cheng, A., Yan, H., Han, C., Wang, W., Tian, Y., Chen, X., 2014. Polyphenols from blueberries modulate inflammation cytokines in LPS-induced RAW264.7 macrophages. Int. J. Biol. Macromol. 69, 382-387

Guo, Y.S., Zhao, Y.H., Fu, J.X., Huang, S.S., Wang, Y., Lu, B.B., Pan, L.J. and Liu, C.M. 2012. Identification of stable QTLs related to trunk girth in longan. Scientia Hort. 134:248-252.

Han, D.M., Guo, D.L., Pang, X.W., Li, R. and Li, J.G. 2011. Influences of fruit development progress on the physiological abscission and maturity of different varieties of longan. Guangdong Agric. Sci. 38(7):59-62.

Han, D.M., Li, J.G., Li, R., Wu, Z.X., Pan, X.W. and Guo, D. 2010. Comparative studies on the fruit storability among different longan varieties. J. South China Agric. Univ. 31(4):6-11.

Han, D.M., Wu, Z.X, Ji, Z.L., Cai, C.H, Yi, G.J., Huo, H.Q. and Wang, X.R. 2000. Effects of $\mathrm{SO}_{2}$ treatment on the overall quality of longan fruits (cv. 'Shixia') during cold storage. First Intel. Symp. on Litchi and Longan, Guangzhou, China.

Holcroft, D.M., Lin, H.T. and Ketsa, S. 2005. Harvesting and Storage. In: C.M. 
Menzel and G.K. Waite (Eds.), Litchi and longan: Botany, cultivation and uses. CAB International, Wallingford, UK. Pp. 273-295.

Huang, 1999. The influence of C-terminal extension on the structure of the "Jdomain" in E. coli DNA. J. Protein Sci, 8: 203-214.

Huang H.B. 1995. Advances in fruit physiology of the arillate fruits of litchi and longan. Annu Rev Hortic Sci, 1: 101-120.

Jiang YM, Zhang ZQ, Joyce DC, Ketsa S. 2002. Postharvest biology and handling of longan fruit (Dimocarpus longan lour). Posthar. Biol Technol. 26: 241252.

Koslanund, R., Karunsatitchai, A., Dejnumbun, W. 2008. Acid dip a new alternative method to replace $\mathrm{SO}_{2}$ fumigation in longan. Agric. Sci. J. 39 (Suppl.), 39-42.

Li, X.H., Chen, S.W., Lai, H.L., Zheng, H.D., Chen, X.Y., Zhuo, Y.Z. and Yu, X.R. 2009. Test of formulated fertilisation on longan. Guangdong Agric. Sci. 10:9596.

Lin, H.T., Chen, S.J., Chen, J.Q. and Hong, Q.Z. 2001a. Current situation and advances in postharvest storage and transportation technology of longan fruit. Acta Hort. 558:343-351.

Marisa M. Wall. 2006. Ascorbic acid and mineral composition of longan (Dimocarpus longan), lychee (Litchi chinensis) and rambutan (Nephelium lappaceum) cultivars grown in Hawaii. J. Food Compost. Anal. 19: 655 - 663.

Menzel, C.M., Waite, G.K., 2005. Litchi and Longan-Botany Production and Uses. CABI publishing, UK, p. 26.

Mo, D.W. 2011. Effect of bagging on quality and size of 'Shixia' longan fruit. Northern Hort. 12:36-38.

Pei, D. T., Li C.B. and Liang X. F., 1997. Study on the stage development of fruit of 'Chuliang' longan. South China Fruits 26: 34.

Pham, V.T., Tran, M.H., Herrero, H., Hormaza, J.I., 2013. The reproductive biology of the Longan. In: Proceedings of the 5th National Scientific Conference on Ecology Biological Resources, Hanoi, 18 October 2013, pp. 1242-1246.

Prasad, K. and Sharma, R. R. 2016. Screening of mango genotypes for the incidence of lenticel browning, a new postharvest problem. Indian J. Agric. Sci. 86 (9) 1169-71.

Prasad, K., Sharma, R. R. and Srivastava, M. 2016a. Postharvest treatment of antioxidant reduces lenticel browning and improves the cosmetic appeal of mango (Mangifera indica L.) fruits without impairing quality. J. Food Sci. and Technol, 53(7): 2995-3001.

Prasad, K., Mahesh, B., Neha, P. 2016 b. Evaluation of okra varieties for yield and quality traits cultivated under hill zone of Karnataka, India. The Bioscan 11: 1131-1136.

Qiu, D.L. 2014. Longan Production and Research in China. Acta Hort. 1029: 3946.

Shi, S. Y., Li, W. C., Zhang, H. N., Liu, L. Q., Shu, B., Liang, Q. Z., Xie, J. H., Wei, Y. Z. 2015. Application of extended Biologische Bundesantalt, Bundessortenamt and Chemische Industrie scale for phenological studies in longan (Dimocarpus longan). Annals Appl. Biol. 167(1):127-134.

Subhadrabandhu, S. 1990. Lychee and Longan Cultivation in Thailand. Rumthai Publishers, Bangkok, Thailand, pp. 40.

Tongdee, S.C., 1994. Sulphur dioxide fumigation in postharvest handling of fresh longan and lychee for export. In: Champ, B.R., Highley, E., Johnson, G.I. (Eds), Postharvest Handling of Tropical 
Fruit. ACIAR Proceedings, vol. 50. Chiang Mai, Thailand, July 19e23, 1993, pp. 186-195.

Whangchai, K., Saengnil, K., Uthaibutra, J., 2006. Effects of ozone in combination with some organic acids on the control of postharvest decay and pericarp browning of longan fruits. Crop Prot. 25, 821-825.

Wu, Z.X., Han D. M., Ji Z.L. and Chen W. X., 1999. Effect of sulphur dioxide treatment on enzymatic browning of longan pericarp during storage. Acta Hortic. Sinica 26: 91-95.

Xu, L. 2004. Development strategies of fujian late-maturing longan. Fujian Fruits 3: $39-40$.

Zheng, J.S., Zhao, Y.F., Lin, H.T., Lin, W.Z., Zhuang, W.D. and Tang, H.L. 2009. Effects of bagging time on growth, development and quality of 'Lidongben' longan fruit. Chinese J. Trop. Crops, 30(9): 1232-1237.

\section{How to cite this article:}

Prasad, K., Pallavi Neha, Milan Kumar Lal and Abhay Kumar Gaurav. 2017. Longan (Dimocarpus longan Lour) Processing: A Review. Int.J.Curr.Microbiol.App.Sci. 6(8): 38-44. doi: https://doi.org/10.20546/ijcmas.2017.608.006 